\title{
Role of omega 3 fatty acids on pregnancy outcome
}

\author{
Sirisha Anne ${ }^{1 *}$, Aruna Menon², Sameena Parikh³ \\ ${ }^{1}$ Department of Obstetrics and Gynecology, Military Hospital Kirkee, Pune, Maharashtra, India \\ ${ }^{2}$ Department of Obstetrics and Gynecology, INHS, Ashwini, Mumbai, Maharashtra, India \\ ${ }^{3}$ Department of Obstetrics and Gynecology, Government Multispeciality Hospital, Chandigarh, India
}

Received: 20 September 2017

Accepted: 20 October 2017

\section{*Correspondence:}

Dr. Sirisha Anne,

E-mail: siri1407@gmail.com

Copyright: (c) the author(s), publisher and licensee Medip Academy. This is an open-access article distributed under the terms of the Creative Commons Attribution Non-Commercial License, which permits unrestricted non-commercial use, distribution, and reproduction in any medium, provided the original work is properly cited.

\section{ABSTRACT}

Background: Maternal nutrition plays a crucial role on influencing fetal growth and birth outcome. Any nutritional insult during critical periods of gestation is known to influence fetal development and increases the risk for development of diseases in later life. Omega 3 and omega 6 fatty acids have been studied to effect fetal growth and development. The balance between these two fatty acids have a definite effect on fetal growth and duration of gestation. Dietary intake of omega 3 fatty acids is less as compared to omega 6 fatty acids due to varied dietary sources.

Methods: A study was conducted at a tertiary care hospital to study the pregnancy outcome in terms of neonatal birth weight and duration of gestation. A total of 200 patients were recruited into the study and divided into two groups by randomised alternative method. One group of 100 patients were supplemented with Omega 3 fatty acids and the other group was not supplemented. Both groups were followed till delivery and their duration of gestation and neonatal birth weight were studied and analysed.

Results: The study showed that $78.8 \%$ patients supplemented with omega 3 fatty acids achieved neonatal birth weight more than $2.5 \mathrm{Kg}$ compared to $50 \%$ of patients who were not supplemented. No significant difference on duration of gestation was found in both the groups.

Conclusions: Supplementation of Omega 3 fatty acids to patients in our study has shown to increase neonatal birth weight compared to patients who have not been supplemented, and did not show any significance in prolonging duration of gestation.

Keywords: Neonatal birth weight, Omega 3 fatty acids, Pre term labour

\section{INTRODUCTION}

Maternal diet is critical for a successful pregnancy as well as fetal health outcomes. Omega -3 fatty acids play a crucial role during fetal growth and neuro cognitive development. ${ }^{1}$ Higher dietary intake of omega 3 fatty acids as in maternal fish consumption has been associated with fetal growth and longer duration of gestation. ${ }^{2}$ Fish is the main source of omega 3 fatty acids and a significant part of the population in developing countries do not consume fish in their regular diet. Fetal growth has been studied as the balance between omega 3 and omega 6 fatty acids, in which if omega 3 fatty acids are more helpful for the growth and development. Omega-3 fatty acid EPA (Eicosapentanoic Acid) and the omega-6 fatty acid AA (Arachidonic Acid) are essential structural components of every cell in the body. Both EPA and AA serve as precursors for biologically active compounds called eicosanoids. ${ }^{2}$ Eicosanoids are localized tissue hormones that seem to be one of the fundamental regulatory classes of molecule in most higher forms of life. They do not travel in the blood, but are created in the cells to regulate a large 
number of processes, including the movement of calcium and other substances into and out of cells, dilation and contraction of muscles, inhibition and promotion of clotting, regulation of secretions including digestive juices and hormones, and, the control of fertility, cell division, and growth. ${ }^{3}$

Birth weight is a very important parameter for neonatal morbidity and mortality and maternal nutrition plays a very important role in neonatal birth weight. The hypothesis of protective effect of fish oil against hypertensive disorders in pregnancy and fetal growth retardation dates back to 1980 that women living on the Faroe Islands delivered babies that were heavier than babies born in Denmark. ${ }^{4}$ The Faroese diet had substantially more omega- 3 fatty acids and less omega- 6 fatty acids than a Danish diet. Omega 3 and Omega 6 fatty acids are metabolized into various eicosanoids (thromboxanes, prostaglandins and leukotrienes) by the same enzymes. The eicosanoids produced by the Omega 6 fatty acids are inflammatory in nature and those produced by omega 3 fatty acids are anti-inflammatory in nature, thus they antagonize each other. In addition to affecting eicosanoid production, EPA also affects lipoprotein metabolism and decreases the production of other compounds including cytokines, interleukin $1 \beta$ (IL-1 $\beta$ ), and tumor necrosis factor $\alpha(\mathrm{TNF}-\alpha)$ which have proinflammatory effects. ${ }^{5}$ These compounds exert proinflammatory cellular actions that include stimulating the production of collagenase and increasing the expression of adhesion molecules necessary for leukocyte extravasation. The mechanism responsible for the suppression of cytokine production by omega-3 LC PUFAs remains unknown, although suppression of eicosanoid production by omega- 3 fatty acids may be involved. It is the ratio of these fatty acids which is significant for outcome of pregnancy. ${ }^{6}$

Essential fatty acid derived eicosanoids play important roles as biochemical mediators in normal term labor that initiate uterine contractions, cervical maturation, and rupture of membranes. ${ }^{7}$ There is an elevation of omega- 6 fatty acid eicosansoid series (PGE2 and PGF2alpha, LTC4, LTB4) in the maternal circulation prior to the onset of labor and inhibition of their synthesis with cyclooxygenase inhibitors stops the onset of labor. ${ }^{8}$ Women who deliver prematurely have higher erythrocyte total plasma lipid omega- 6 fatty acids and lower omega -3 fatty acids compared with women who delivered at term, suggesting that an imbalance in favor of omega- 6 fatty acids and their eicosanoid derivatives contribute to the premature onset of labor. ${ }^{9}$ By altering the balance of omega- 6 to omega- 3 eicosanoids by diet supplementation with omega 3 fatty acids in human, rodent, and sheep, studies have been successful in increasing the duration of gestation. It also increases placental blood flow which helps in increasing birth weight. ${ }^{10}$ The mechanisms by which omega-3 fatty acids or their eicosanoid derivatives impact the observed biological outcomes may include one or more of their identified functions in modulating the cell membrane microenviroment, signaling pathways, and gene expression. ${ }^{7}$ The various ways in which omega-3 fatty acids affect maternal and child health is primarily by their anti inflammatory actions by which preterm birth is prevented and thus helps in increasing the duration of gestation. $^{11}$

\section{Dietary intake of omega 3 fatty acids}

Of all fats found in food, two-alpha-linolenic acid and linoleic acid cannot be synthesized in the human body, yet these are necessary for proper physiological functioning. These two fats are thus called essential fatty acids. Both ALA and LA are present in a variety of foods. Omega- 6 fatty acids can be found in the vegetable oils used in processed foods, fried foods, and condiments like salad dressings. ${ }^{12}$ One teaspoon of corn oil can satisfy the daily omega- 6 requirement, but most individuals eat 10 to 20 times that amount. ${ }^{12}$

In contrast, the intake of omega-3 fatty acids is suboptimal. The richest dietary sources of omega- 3 fatty acids are from marine sources, fish oil supplements, and selected vegetable oils like flaxseed (57\% omega-3 fatty acids), canola ( $11 \%$ omega-3 fatty acids), and soybean ( $8 \%$ omega-3 fatty acids). Most individuals do not consume these omega-3-rich foods on a regular basis ${ }^{12}$. The ratio of dietary omega- 6/omega-3 fatty acids in the American diet approximates 10 to $25: 1$. Some novelty oils, such as flaxseed oil, contain relatively high concentrations of ALA, but these oils are not commonly found in the food supply. A healthy diet should consist of roughly 2-4 times more omega- 6 fatty acids than omega- 3 fatty acids. The typical diet tends to contain 14 - 25 times more omega- 6 fatty acids than omega- 3 fatty acids.

\section{METHODS}

A prospective cohort study was conducted at a tertiary care hospital and affiliated hospital between September 2008 and March 2010. The study population comprised of 200 women who were regularly attending ANC OPD according to the inclusion criteria. The inclusion criteria were ladies with singleton pregnancy booked in first trimester. The exclusion criteria were multiple gestation, gestational diabetes, congenital anomalies of fetus, cardiovascular diseases and placenta praevia which can have an impact on the pregnancy outcome. The subjects were enlisted after signing an informed consent form.

The subjects were divided in two groups by randomised alternative method. One group of 100 patients was supplemented with Omega 3 fatty acid capsules (MEGA3) which contains Eicosa Pentanoic Acid (EPA) 180mg and Docosahexanoic acid (DHA) 120mg once daily. Supplementation was started in first trimester at the first visit of the patient to the hospital along with other supplements. To the other group omega 3 fatty acids supplementation was not given, and only iron and calcium supplementation was given. 
Both group of patients were followed up throughout pregnancy in the antenatal OPD once monthly till 28 weeks once fortnightly from 28 weeks to 36 weeks and once weekly till 40 weeks. Blood pressure of all patients was taken at every visit. Ultrasonography was done atleast once in every trimester of pregnancy was uneventful and more frequently if IUGR is suspected. Both group of patients were followed up till delivery and outcomes were studied in the form of neonatal birth weight and duration of gestation.

\section{Statistical analysis}

Data analysis was done by independent samples test and group statistics. All hypothesis tests were two sided and $\mathrm{P}<0.05$ was considered statistically significant.

\section{RESULTS}

200 subjects were recruited into the study, out of which 100 patients were given MEGA 3 capsules by randomised alternative method. These patients were followed upto delivery and outcome studied in respect to neonatal birth weight and duration of gestation. The overall mean age of the subjects was 24.95 years.

Table 1: Birth weight.

\begin{tabular}{|c|c|c|c|}
\hline \multirow[t]{2}{*}{$\begin{array}{l}\text { Birth weight } \\
\text { category } 1\end{array}$} & \multicolumn{2}{|l|}{ Group } & \multirow[t]{2}{*}{ Total } \\
\hline & $\begin{array}{l}\text { Omega } 3 \\
\text { fatty acids }\end{array}$ & $\begin{array}{l}\text { No Omega } \\
3 \text { fatty acid }\end{array}$ & \\
\hline \multicolumn{4}{|l|}{ LBW } \\
\hline Number & 21 & 50 & 71 \\
\hline$\%$ & 21.2 & 50.0 & 35.7 \\
\hline \multicolumn{4}{|l|}{ NBW } \\
\hline Number & 78 & 50 & 128 \\
\hline$\%$ & 78.8 & 50.0 & 64.3 \\
\hline \multicolumn{4}{|l|}{ Total } \\
\hline Number & 99 & 100 & 199 \\
\hline$\%$ & 100.0 & 100.0 & 100.0 \\
\hline
\end{tabular}

Percentage of LBW is significantly higher in No Fish Oil group; $\mathrm{p}=0.000$.

21 patients out of 100 patients supplemented with omega 3 fatty acids had low neonatal birth weight compared to 50 patients who were not supplemented with omega 3 fatty acids. 78 patients $(78.8 \%)$ supplemented with omega 3 fatty acids had normal birth weight $(>2500 \mathrm{gm}) .50 \%$ of patients not supplemented with omega 3 fatty acids had normal birth weight.

$63.6 \%$ of patients supplemented with omega 3 fatty acids had average birth weight between 2500-2999gm. Only $4 \%$ of patients had birth weight less than $2000 \mathrm{gm} .15 .2 \%$ of patients had birth weight more than $3000 \mathrm{gm}$.

$47 \%$ of patients not supplemented with omega 3 fatty acids had birth weight between $2500-2999 \mathrm{gm}$. A significant percentage of $16 \%$ of patients had low birth weight
$(<2000 \mathrm{gm})$. Only 3 patients $(3 \%)$ in the group not supplemented with omega 3 fatty acids had birth weight more than $3000 \mathrm{gm}$.

Table 2: Birth weight by group.

\begin{tabular}{|llll|}
\hline $\begin{array}{l}\text { Birth weight } \\
\text { category 1 }\end{array}$ & $\begin{array}{l}\text { Group } \\
\text { Omega 3 } \\
\text { fatty acids }\end{array}$ & $\begin{array}{l}\text { no Omega } \\
\text { 3 fatty } \\
\text { acids }\end{array}$ & \\
\hline$<\mathbf{2 0 0 0}$ g & & 16 & \\
\hline Number & 4 & 16.0 & 20 \\
\hline$\%$ & 4.0 & & 10.1 \\
\hline $\mathbf{2 0 0 0}-\mathbf{2 4 9 9} \mathbf{g}$ & & 34 & 51 \\
\hline Number & 17 & 34.0 & 25.6 \\
\hline$\%$ & 17.2 & & 110 \\
\hline $\mathbf{2 5 0 0}-\mathbf{2 9 9 9}$ g & & 47 & 55.3 \\
\hline Number & 63 & 47.0 & 18 \\
\hline$\%$ & 63.6 & & 9.0 \\
\hline $\mathbf{3 0 0 0}+\mathbf{g}$ & & 3 & 199 \\
\hline Number & 15 & 3.0 & 100.0 \\
\hline$\%$ & 15.2 & 100 & \\
\hline Total & & 100.0 & \\
\hline Number & 99 & & \\
\hline$\%$ & 100.0 & & \\
\hline
\end{tabular}

Table 3: Period of gestation.

\begin{tabular}{|llll|}
\hline $\begin{array}{l}\text { POG (days) } \\
\text { category }\end{array}$ & $\begin{array}{l}\text { Group } \\
\text { Omega 3 } \\
\text { fatty acids }\end{array}$ & $\begin{array}{l}\text { no Omega 3 } \\
\text { fatty acids }\end{array}$ \\
\hline Pre-term & \multicolumn{2}{l|}{} \\
\hline Number & 10 & 11 & 21 \\
\hline$\%$ & 10.1 & 11.0 & 10.6 \\
\hline Full Term & & & \\
\hline Number & 89 & 89 & 178 \\
\hline$\%$ & 89.9 & 89.0 & 89.4 \\
\hline Total & & & \\
\hline Number & 99 & 100 & 199 \\
\hline$\%$ & 100.0 & 100.0 & 100.0 \\
\hline
\end{tabular}

Period of gestation in both the groups was almost similar. $87.5 \%$ patients who were not supplemented with omega 3 fatty acids had full term delivery compared to $100 \%$ patients in the supplemented group.

Table 4: Group statistics.

\begin{tabular}{|c|c|c|c|c|}
\hline BWT & Group & $\mathbf{N}$ & Mean & Std. deviatior \\
\hline & $\begin{array}{l}\text { Omega } 3 \\
\text { fatty acids }\end{array}$ & 99 & 2743.99 & 329.307 \\
\hline & $\begin{array}{l}\text { no Omega } 3 \\
\text { fatty acids }\end{array}$ & 100 & 2423.25 & 376.480 \\
\hline
\end{tabular}

The mean birth weight in patients supplemented with omega 3 fatty acids was 2743.99 gms and mean birth weight in the non supplemented group was $2423.25 \mathrm{gms}$. 
Table 5: Independent samples test.

\begin{tabular}{lll} 
& $\mathrm{t}$ & $\mathrm{p}$-value \\
BWT & 6.394 & 0.000 \\
\hline
\end{tabular}

$\mathrm{P}$-value is 0.000 which is significant for the study.

\section{DISCUSSION}

The results of the study suggest that increased intake of omega 3 fatty acids can prevent low birth weight. This is in line with earlier studies. However, in this study omega 3 fatty acids had no effect on duration of gestation since $89 \%$ of patients in both groups achieved normal delivery.

Observational studies on fish intake and randomised trials on fish oil supplementation generally have not supported a protective effect. A more recent study, however found a Ushaped association with greater risk of hypertensive disorders among women with lowest and highest intake of omega 3 fatty acids. ${ }^{2}$ A Danish study done in 1980's showed that women living on the Faroe Islands delivered babies that were $194 \mathrm{~g}$ heavier than babies born in Denmark. $^{4}$ The Faroese diet had substantially more omega-3 fatty acids and less omega- 6 fatty acids than a Danish diet. An Indian study done by Muthayya and co workers showed that women who had low intake of fish during third trimester had higher risk of low birth weight. ${ }^{3}$ Olsen SF et al, showed in a randomized controlled trial done in Denmark that there was increase in birth weight by $107 \mathrm{gm}$ in patients supplemented with fish oil. ${ }^{11}$ A meta analysis done in 2007 by Horvath and co workers suggested that there was no difference in infant birth weight between patients who were supplemented with omega 3 fatty acids and those who were not. ${ }^{13}$ The present study suggests that there is significant difference in birth weight between both the groups with an average gain of 320.74 gms in the supplemented group.

Duration of gestation was almost similar in both the groups. Total number of preterm deliveries were 21. Out of them $11 \%$ had preterm delivery in the nonsupplemented group and $10.1 \%$ in the supplemented group had preterm delivery. An observational study done in Denmark by Olsen and coworkers suggested that there was no significant increase in gestational age with consumption of omega 3 fatty acids ${ }^{14}$. A study done in Faroe Islands by Grandjean and coworkers suggests that a higher intake of marine fats (fish and whale) was associated with a slight prolongation of gestation (1.5days). In a randomized, double-blind, placebocontrolled UK trial done by Onwude and co workers in which women with high-risk pregnancies received either fish oil or placebo until 38 week of gestation, there was no effect of fish oil on duration of gestation. ${ }^{15}$ A study published by Olsen et al suggests that an average increase by 4 days gestation in patients supplemented with omega 3 fatty acids. ${ }^{9}$ The present study suggests no significant difference in duration of gestation between both groups.
Present findings suggest that supplementation of omega 3 fatty acids has a definite role neonatal birth weight and has no significant role on duration of gestation. Only $21.2 \%$ patients in the study group had low birth weight compared to $50 \%$ in the control group.

The present study is a pilot study with a small sample size of 200 patients. Most studies quoted in the literature are community based studies where a larger population was taken into consideration. Further studies are required at a larger scale to study the outcome of pregnancy in patients supplemented with Omega 3 fatty acids. There were no side effects of the drug in the study group. Hence it can be supplemented to patients with high risk factors.

There are various confounding factors like age, pre pregnancy weight, parity, gender of the child, genetics which have an impact on birth weight of the neonate and other outcomes like preterm labour or gestational hypertension etc. Randomisation of the patients was done by alternative method; hence it was assumed that all these factors were also randomised accordingly though the number of patients was only 200 (test and control). However further studies involving a large number may be at community level; are required to neutralize these variables and attribute the outcome to omega 3 fatty acid supplementation-a nutritional supplement.

Supplementation of omega 3 fatty acids in the present study was done by MEGA 3 capsules which contained Eicosa Pentanoic Acid (EPA) 180mg and Docosahexanoic acid (DHA) 120mg once daily to the study group. Most of the studies quoted in the literature were based on increased intake of marine fish and fish oil wherein quantification of the amount of omega 3 fatty acids was not done. Amount of omega 3 fatty acid supplementation was not exactly studied in previous studies. Amount of supplementation in the present study was assumed to have a healthy balance between omega 3 and omega 6 fatty acid derivatives.

No biochemical tests were done to ensure that patients were taking the drug. Maternal DHA levels were not measured to ensure compliance neither the levels were measured before starting the medication. Dietary intake of omega 3 fatty acids in control group was not studied in the form of amount of fish intake or intake of flax seed oil.

Uteroplacental transfer of omega 3 fatty acids also could not be established since umbilical cord blood DHA levels were not measured due to lack of facilities.

Growth potential of the neonates depends on many factors including influence of genetics; hence genetic influence on birth weight cannot be ruled out.

Also, other complications in neonates like retinopathy, intraventricular hemorrhage, long term mile stones including neonatal neurodevelopment which were also studied earlier to have beneficial effects by supplementation with omega 3 fatty acids could not be 
studied in this study due to paucity of time and supplementation was not carried out postnatally.

\section{CONCLUSION}

The results of the study demonstrate that omega 3 fatty acid supplementation during pregnancy in women have a beneficial effect on neonatal birth weight and decrease morbidity associated with low birth weight.The study could not prove any effect on prolonging duration of gestation and preventing preterm labour.

Funding: No funding sources Conflict of interest: None declared

Ethical approval: The study was approved by the Institutional Ethics Committee

\section{REFERENCES}

1. Nordgren TM, Lyden E, Anderson-Berry A, Hanson C. Omega-3 fatty acid intake of pregnant women and women of childbearing age in the united states: potential for deficiency?. Nutrients. 2017 Feb 26;9(3):197.

2. Fereidooni B, Jenabi E. The use of omega 3 on pregnancy outcomes: a single-center study. J Pak Med Assoc. 2014 Dec 1;64(12):1363-5.

3. Innis S, Uauy R. Mechanisms of action of LCPUFA effects on infant growth and neurodevelopment: perinatal biochemistry and physiology of LCPUFA discussion. J Pediatr. 2003 Oct 31;143(4):96-109.

4. McCormick MC. The contribution of low birth weight to infant mortality and childhood morbidity. N Eng J Med. 1985 Jan 10;312(2):82-90.

5. Olsen S, Sorensen TA, Secher N, Hansen H, Jensen $\mathrm{B}$, Sommer $\mathrm{S}$ et al. Intake of marine fat, rich in (n-3)polyunsaturated fatty acids, may increase birthweight by prolonging gestation. Lancet. 1986 Aug 16;328(8503):367-9.

6. Holman RT. The slow discovery of the importance of $\omega 3$ essential fatty acids in human health. J Nutr. 1998 Feb 1;128(2):427S-33S.
7. Decsi T, Koletzko B. Growth, fatty acid composition of plasma lipid classes, and plasma retinol and alphatocopherol concentrations in full-term infants fed formula enriched with omega- 6 and omega- 3 longchain polyunsaturated fatty acids. Acta Paediatr. 1995;84(7):725-32.

8. Birch EE, Hoffman DR, Uauy R, Birch DG, Prestidge C. Visual acuity and the essentiality of docosahexaenoic acid and arachidonic acid in the diet of term infants. Pediatr Res. 1998 Aug 1;44(2):201-9.

9. Makrides M, Neumann MA, Simmer K, Gibson RA. Dietary long-chain polyunsaturated fatty acids do not influence growth of term infants: A randomized clinical trial. Pediatrics. 1999;104(3 Pt 1):468-75.

10. Dunstan JA, Mori TA, Barden A, Beilin LJ, Holt PG, Calder PC, et al. Effects of n-3 polyunsaturated fatty acid supplementation in pregnancy on maternal and fetal erythrocyte fatty composition. Eur J Clin Nutr. 2004;58(3):429-37.

11. Burdge G. Alpha-linolenic acid metabolism in men and women: nutritional and biological implications. Curren Opin Clin Nutr Metab Care. 2004 Mar;7(2):137-40.

12. Bell SJ, Bradley D, Forse RA, Bistrian BR. The new dietary fats in health and disease. J Am Diet Assoc. 1997 Mar;97(3):280-6.

13. Carlson SE, Rhodes PG, Ferguson MG. Docosahexaenoic acid status of preterm infants at birth and following feeding with human milk or formula. Am J Clin Nutr. 1986;44(6):798-804.

14. Anderson JW, Johnstone BM, Remley DT. Breastfeeding and cognitive development: A meta-analysis. Am J Clin Nutr .1999;70(4)

15. Dyerberg J, Bang HO, Walters BN, Walters T, Atallah A, Schinnar R et al. Pre-eclampsia and prostaglandins. The Lancet. 1985 Jun 1;325(8440):1267-8.

Cite this article as: Anne S, Menon A, Parikh S. Role of omega 3 fatty acids on pregnancy outcome. Int J Reprod Contracept Obstet Gynecol 2017;6:5396-400 